\title{
Vitamin $D$ deficiency in refugees in Italy
}

\author{
L.G. De Filippis ${ }^{1,2}$, I. Trombetta ${ }^{2}$, T. Novella ${ }^{2}$, M. Alampi ${ }^{3}$ \\ ${ }^{1}$ COOPISA Association, Reggio Calabria; '2Service for protection of refugees and asylum seekers (SPRAR), \\ Projects of S. Alessio in Aspromonte (RC) and Laganadi $(R C)$; ' 3 Service for protection of refugees \\ and asylum seekers (SPRAR), Project of Campo Calabro (RC), Italy
}

\begin{abstract}
SUMMARY
The objective of the research is to determine 25[OH]D serum levels in refugees in Italy.

In the following research we have taken into consideration the results of the monitoring of Vitamin D levels in 46 refugees of the Italian Service for protection of refugees and asylum seekers (SPRAR) system. The indicator of overall vitamin D status used was the circulating serum level of 25(OH)D. Data was analyzed using Microsoft Excel.

In the refugees tested, the mean level of $25(\mathrm{OH}) \mathrm{D}$ resulted $9.18 \mathrm{ng} / \mathrm{mL}$. The standard deviation was 4.8 , with a minimal level of 4.3 and a maximum of 27.4. This figure indicates a clear condition of hypovitaminosis in refugees.

While it is general assumption that migratory phenomena may induce the spread of tropical or infectious diseases, widely attested literature demonstrates how chronic pathologies and diseases related to altered lifestyles are the most relevant for Italian case records. Indeed, among the aforementioned diseases, Vitamin D deficiency so far lacks acknowledgement at a national level. Considering the results of lower-than-desirable vitamin D levels found in refugees in Italy, it is necessary to take this parameter into consideration when analyzing individuals who have faced migratory phenomena in order to mitigate the effects of hypovitaminosis D.
\end{abstract}

Key words: Vitamin D; Refugees; Salgari syndrome.

\section{INTRODUCTION}

W hen discussing the health of migrants, the attention is generally oriented to tropical and/or infectious diseases. Yet, while this remains true only in the general public opinion and not in that of experts and professionals of the field of migration, around 20 years ago the types of doctors who were involved in the subject of migrants' health were specialists in tropical and infectious diseases. Shortly after, this phenomenon became well known as the Salgari syndrome (1) (Figure 1), characterized by the obsessive and methodical research and diagnosis of tropical diseases in migrants, who were often not affected by any of these (2).

Research shows that instead the main issues that require medical intervention in migrants, and more specifically in refugees, are heart diseases, chronic diseases, and cancer (3).

One non-infectious disease that has been well analyzed in refugee populations internationally (probably as a result of the increased possibilities of analyzing this segment of the population), but not yet in Italy, is hypovitaminosis D. In fact, several studies have shown how levels of 25-dihydroxycholecalciferol in refugees were lower than standard, and more specifically lower than the correspondent local individuals in the same age groups (4-7).

These results become very relevant for global health when considering the importance of vitamin D for skeletal health, for the immune system, for the functioning of the cardiovascular system, and last but not least for its protective functions (8) in pregnant women, especially considering that a very high number of refugees are fertile women.

\section{MATERIALS AND METHODS}

\section{Participants}

The research involved the analysis of 46 migrants (of whom 40 were men and 6 were women, with an average age of 25.6 years). The individuals analysed were part
Corresponding author Luigi G. De Filippis COOPISA Association Service for protection of refugees and asylum seekers (SPRAR),

Projects of $\mathrm{S}$. Alessio in Aspromonte (RC) and Laganadi (RC), Italy E-mail: lgdef@yahoo.it 


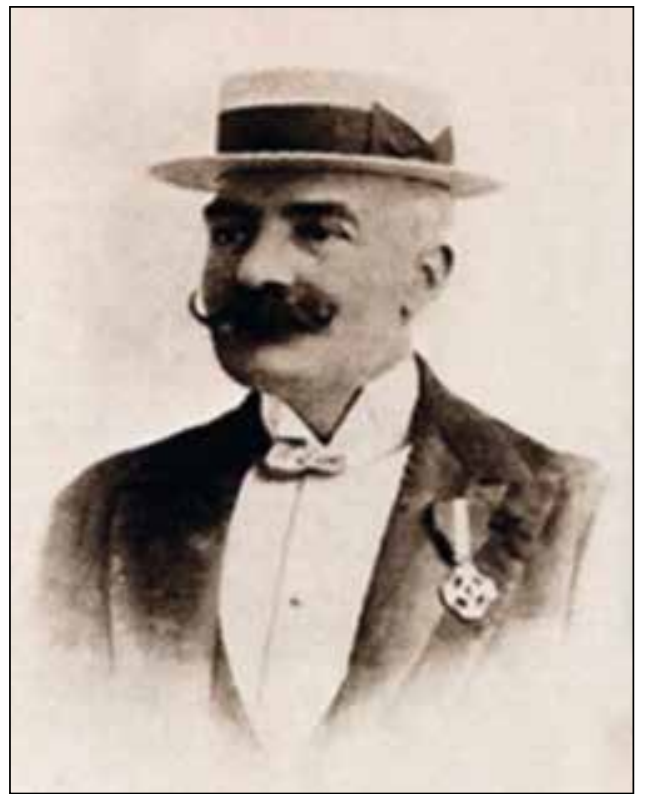

Figure 1 - Emilio Salgari (1862-1911) was an Italian writer of action adventures, whose work made entire generations dream of the exotic landscapes he described, even though the only trip he went on was up and down the Adriatic coasts of Italy on board of Italia Una. But what is the connection between Salgari and migrants' healthcare problems? Around 20 years ago, when the political debate on migrants' health started in Italy, it focused on the fear of mysterious exotic illnesses that could have arrived with the migrants. Francesco De Lorenzo, then minister of health, created the first state commission to face the topic of migrants' health, and it is not surprising that the doctors involved were almost exclusively specialists in tropical and infectious diseases.

of the Service for protection of refugees and asylum seekers (SPRAR) projects in the province of Reggio Calabria (Italy). The countries of origin of them include Afghanistan, the Ivory Coast, Egypt, the Gambia, Ghana, Guinea, Iraq, Mali, Nigeria, Pakistan, and Somalia. The analysis was performed within 2 and 18 months of their arrival in Italy, during general examinations or those for specific pathologies (Table I).

A limit of this study was that, due to the purposes of the exams for general checkup, further related biochemical markers, like PTH and bone turnover markers, were not studied.

The 25(OH)D assay and statisticl analysis: The most valid indicator of vitamin D status is the circulating serum level of $25(\mathrm{OH})$ D (9). The method used in the laboratory was chemiluminescence immunoassay. The data were then analysed using Microsoft Excel.

\section{Location}

SPRAR Projects of S. Alessio, Laganadi, Campo Calabro, Africo (RC, Italy).

\section{RESULTS}

\section{Participants}

Forty-six guests of the SPRAR system of the province of Reggio Calabria (Italy) were analysed. Of these, 40 were men $(86.95 \%)$ and 6 were women $(13.04 \%)$. Among the comorbidities, $44 \%$ of the patients presented psychiatric disorders (due to the common presence of the post-traumatic stress disorder in migrants), $8.6 \%$ of the patients presented (inactive) tuberculosis, $4.3 \%$ of the patients presented hepatitis $\mathrm{B}$, and $4.3 \%$ of the patients presented HIV infection. As already stated, the refugees were mostly from Sub-Saharan African countries and Pakistan.

\section{Mean levels of 25(OH)D}

In the refugees tested, the mean level of $25(\mathrm{OH}) \mathrm{D}$ resulted $9.18 \mathrm{ng} / \mathrm{mL}$. The standards used indicated serum levels of $25(\mathrm{OH}) \mathrm{D}$ lower than $<10$ as deficiency, and

Table I - Region of origin, by age groups.

\begin{tabular}{|c|c|c|c|c|}
\hline \multirow{2}{*}{ Age } & \multicolumn{4}{|c|}{ Total (N=46) } \\
\cline { 2 - 5 } & Sub-Saharan Africa (N=22) & Asia (N=22) & Maghreb And Middle East (N=4) & \\
\hline $18-20$ & 6 & 2 & 0 & 8 \\
\hline $20-39$ & 14 & 20 & 1 & 33 \\
\hline $40-45$ & 0 & 2 & 1 & 3 \\
\hline
\end{tabular}


Table II - Statistical analysis.

\begin{tabular}{|l|l|}
\hline Simple standard deviation & 4.80 \\
\hline Variance (sample standard), s2 & 23.13 \\
\hline Mean (average) & 9.18 \\
\hline Standard error of the mean & 0.70 \\
\hline
\end{tabular}

levels between 10-30 as insufficiency (10). The resulting mean of $9.18 \mathrm{ng} / \mathrm{mL}$ serum levels of $25(\mathrm{OH}) \mathrm{D}$ in refugees is therefore clearly deficient (Table II).

\section{DISCUSSION} AND CONCLUSIONS

The general discourse on migrants' healthcare is often focused on diseases of infectious origin which, in reality, are not the most common in migration-related medical experience. Data analysis in academic literature focus instead on how the aetiology for poor health conditions in migrants is to be sought in diseases related to low quality of life, malnutrition, and distress. These diseases contributed to the spoiling of the conditions that enabled the creation of the so-called healthy migrant effect, which is the circumstance in which the migrants who come to Italy have a better health status compared to other individuals of the same sex and age.

To our knowledge no studies have been conducted on vitamin D levels in migrants, and more specifically in refugees in Italy. Nevertheless, the predisposition of migrants to present deficiencies of vitamin D can be easily estimated by considering such factors as religious and cultural practices or climate, which can reduce their exposition to the sunlight (11-13). Further studies also demonstrate how individuals with higher skin pigmentation have a less efficient production of vitamin D compared to individuals of Caucasian descent (14). Finally, social and economic conditions were also proven to be directly proportional to the levels of vitamin $\mathrm{D}$, and in fact refugees come most frequently from lower income scenarios (15).

Although limited to a small sample of the refugee population, the data collected in the present research are perfectly con- sistent with international literature on the matter, and certainly constitute a first step towards a greater awareness of the necessity for healthcare providers to include vitamin $\mathrm{D}$ screening in the initial analysis of refugees and asylum seekers who are part of the National Health Care system, in order to prevent skeletal and non-skeletal conditions, such as cancer (16), multiple sclerosis (17), psychiatric conditions (18), tuberculosis $(19,20)$.

Acknowledgements: the Authors acknowledge Anna Aspesi (SPRAR Africo), Antonia Idone (SPRAR Campo Calabro), and Antonella Attinà (SPRAR $\mathrm{S}$. Alessio) for their precious help in collecting data.

\section{REFERENCES}

1. Geraci S. La sindrome di Salgari 20 anni dopo. Janus. Medicina: cultura, culture. Sanità Meticcia. 2006; 21: 29.

2. Geraci S, Marceca M, Colasanti R. La syndrome di Salgari. Immigrazione e diritto alla salute in Italia. Alfa Zeta. 1991; 9.

3. Geraci S. XV Dossier statistico sull'immigrazione: considerazioni e dati sulla salute degli immigrati. Agenzia Sanitaria. 2005; 43.

4. Aucoin M, Weaver R, Thomas R, Jones L. Vitamin $\mathrm{D}$ status of refugees arriving in Canada: findings from the Calgary Refugee Health Program. Can Fam Physician. 2013; 59: e188-94.

5. Benson J, Skull S. Hiding from the sun - vitamin D deficiency in refugees. Aust Fam Physician. 2007; 36: 355-7.

6. Erkal MZ, Wilde J, Bilgin Y, et al. High prevalence of vitamin D deficiency, secondary hyperparathyroidism and generalized bone pain in Turkish immigrants in Germany: identification of risk factors. Osteoporos Int. 2006; 17 : 1133-40.

7. Skull SA, Ngeow JY, Biggs BA, et al. Vitamin $\mathrm{D}$ deficiency is common and unrecognized among recently arrived adult immigrants from The Horn of Africa. Intern Med J. 2003; 33 : 47-51.

8. Wagner CL, Taylor SN, Johnson DD, Hollis $\mathrm{BW}$. The role of vitamin D in pregnancy and 
lactation: emerging concepts. Women's Health 2012; 8.3.

9. Hollis BW. Assessment of vitamin D nutritional and hormonal status: what to measure and how to do it. Calcif Tissue Int. 1996; 58: 4-5.

10. Adami S, E. Romagnoli, V. Carnevale, et al. Guidelines on prevention and treatment of vitamin D deficiency. Italian Society for osteoporosis, Mineral Metabolism and Bone Diseases (SIOMMMS). Reumatismo. 2011; 63: 129-47.

11. Benson J, Skull S. Hiding from the sun - vitamin D deficiency in refugees. Aust Fam Physician. 2007; 36: 355-7.

12. Erkal MZ, Wilde J, Bilgin Y, et al. High prevalence of vitamin D deficiency, secondary hyperparathyroidism and generalized bone pain in Turkish immigrants in Germany: identification of risk factors. Osteoporos Int. 2006; 17 : 1133-40.

13. Skull SA, Ngeow JY, Biggs BA, et al. Vitamin $\mathrm{D}$ deficiency is common and unrecognized among recently arrived adult immigrants from The Horn of Africa. Intern Med J. 2003; 33: 47-51.
14. Chen TC, Chimeh F, Lu Z, et al. Factors that influence the cutaneous synthesis and dietary sources of vitamin D. Arch Biochem Biophys. 2007; 460: 213-7.

15. Karras S, Paschou SA, Kandaraki E, et al. Hypovitaminosis D in pregnancy in the Mediterranean region: a systematic review. Eur J Clin Nutrition. 2016; 70: 979-86.

16. Garland CF, Garland FC, Gorham ED, et al. The role of vitamin $\mathrm{D}$ in cancer prevention. Am J Public Health 2006; 96: 252-61.

17. Munger KL, Zhang SM, O'Reilly E, et al. Vitamin D intake and incidence of multiple sclerosis. Neurology. 2004; 62: 60-5.

18. Gloth FM III, Alam W, Hollis B. Vitamin D vs. broad spectrum phototherapy in the treatment of seasonal effective disorder. J Nutr Health Aging. 1999; 3: 5-7.

19. Chan TYK. Vitamin D deficiency and susceptibility to tuberculosis. Calcif Tissue Int. 2000; 66: 476-8.

20. Liu PT, Stenger S, Li H, et al. Toll-like receptor triggering of a vitamin D-mediated human antimicrobial response. Science. 2006; 3: 1770-3. 